\title{
Physical and photoelastic properties of bulk-fill and conventional composites
}

This article was published in the following Dove Press journal:

Clinical, Cosmetic and Investigational Dentistry

\section{Renata Pereira' \\ Maria Cecília Caldas \\ Giorgi² $^{2}$ \\ Rodrigo Barros Esteves \\ Lins' \\ Jéssica Dias Theobaldo' \\ Débora Alves Nunes Leite \\ Lima' \\ Giselle Maria Marchi' \\ Flávio Henrique Baggio \\ Aguiar'}

'Department of Restorative Dentistry, Piracicaba Dental School, University of Campinas, Piracicaba, SP 13.4I4903, Brazil; ${ }^{2}$ Department of Operative Dentistry, School of Health Sciences, State University of Amazonas, Manaus, AM 69065-00I, Brazil
Correspondence: Renata Pereira Department of Restorative Dentistry, Piracicaba Dental School, University of Campinas, 90I Avenida Limeira, Areião, PO Box 52, Piracicaba, SP I34| 4-903, Brazil

Tel +55 I9 982। 43025

Fax +55 I9 342। 0144

Email re_pe@hotmail.com
Purpose: This study evaluated the influence of thickness increment on degree of conversion (DC), Knoop microhardness (KHN), and polymerization-shrinkage stress (PSS) by photoelasticity of three dental composites.

Methods: For DC and KHN, 45 samples were prepared and divided into nine groups $(\mathrm{n}=5)$, according to composite (microhybrid [Filtek Z250 - Z250], bulk-fill flowable [SureFil SDR Flow - SDR], and nanohybrid composite [N'Durance - NDU]) and increment thickness $(1,1.5$, and $3 \mathrm{~mm}$ ). PSS was measured by photoelastic analysis. Composites were placed into a photoelastic model cavity and light-cured. DC and KHN data were subjected to two-way ANOVA and Bonferroni post hoc test. PSS results were qualitatively evaluated through Kruskal-Wallis test. Results: SDR showed the highest DC values. At top and bottom surfaces, the highest KHN was obtained by Z250. Z250 showed higher PSS than SDR in $1.5 \mathrm{~mm}$ increments. NDU showed higher PSS than SDR in $3 \mathrm{~mm}$ increments.

Conclusion: The bulk-fill composite demonstrated better DC and similar KHN and PSS in deeper layers compared to conventional composites. Bulk-fill composites may perform as well as conventional nanohybrid and microhybrid composites.

Keywords: composite resins, dental restoration, permanent, dental stress analysis, dentistry, operative

\section{Introduction}

With improvements in adhesive technique and increasing esthetic demand, resin-based composites are indicated for anterior and posterior restorations. ${ }^{1,2}$ Although these materials present suitable mechanical and physical properties, some clinical aspects may determine the success or failure of dental composite restorations. One of these aspects relates to the thickness of the composite increment added to the cavity and thus the effective polymerization of all increments placed. ${ }^{3}$ Appropriate light-curing is crucial for resin-based material to present satisfactory mechanical properties, which clinically provide greater longevity to restoration. ${ }^{3,4}$

Light-curing processes create polymerization-shrinkage stress at adhesive interfaces that may affect marginal integrity and clinical performance. ${ }^{5,6}$ To minimize this effect, layering has been the most indicated technique for placement of resin composites. ${ }^{2}$ This technique aims to enable the complete light-curing of composite increments and reduce shrinkage volume, generating lower polymerization-shrinkage stress. ${ }^{2,7}$ Some studies suggest increments of $2 \mathrm{~mm} .{ }^{8,9}$ However, depending on the cavity depth, increments $<2 \mathrm{~mm}$ should be inserted in the cavity for best polymerization. ${ }^{4}$ 
Nevertheless, the treatment of extensive posterior restorations with direct resin-based composites is time-consuming. ${ }^{10}$ In order to save time and favor clinical procedures, ${ }^{11}$ composites have been modified down the years to allow restoration procedures with increments $>2 \mathrm{~mm}$ or even with a single increment. ${ }^{10,12}$ Bulk-fill composites emerged, allowing the restoration of deep cavities. Increments up to $4 \mathrm{~mm}$ thickness can be properly cured under the right irradiance conditions (exposure times of 40 seconds), with no need of further light exposure. ${ }^{3}$ Studies suggest that changes in the organic matrix composition of these composites allow a greater degree of conversion in greater depths, reduced polymerization shrinkage, and low shrinkage stress. ${ }^{10,13-15}$

In the past few years, shrinkage stress of bulk-fill composites has been evaluated in diverse ways. In 2014, El-Damanhoury and Platt ${ }^{16}$ evaluated polymerization-shrinkage-stress kinetics of bulk-fill composites using tensometry. In 2015, Rosatto et $\mathrm{a}^{15}$ used finite-element analysis to determine shrinkage-stress distributions during restoration with bulk-fill composites, and Fronza et $\mathrm{al}^{13}$ assessed shrinkage stress using composites bonded to acrylic rods attached to a universal testing machine. In 2016, Al Sunbul et $\mathrm{al}^{17}$ in turn measured shrinkage stress using the Bioman instrument. Few studies in literature, however, have used photoelastic analysis to measure shrinkage stress of bulk-fill composites. ${ }^{18,19}$ The great advantage of photoelastic methods is the ability to visualize all internal stresses, ie, to observe stress patterns throughout the whole sample, allowing the researcher to locate, photograph, and measure qualitatively and quantitatively the magnitude of stresses. ${ }^{20,21}$

In consideration of the importance of both reducing polymerization stress and maintaining physical properties of dental composites, the purpose of this study was to evaluate the influence of increment thickness on degree of conversion, Knoop microhardness, and polymerization-shrinkage stress by photoelasticity of three dental composites: a microhybrid (Filtek Z250 [Z250]), a bulk-fill flowable (SureFil SDR Flow [SDR]), and a nanohybrid composite (N'Durance [NDU]). The null hypotheses tested were: 1) the thickness of increments would not affect degree of conversion, microhardness, or polymerization-shrinkage stress of composites; and 2) there would not be significant differences in degree of conversion, microhardness, or polymerization-shrinkage stress among the composite-resin restorative materials.

\section{Methods}

Details of composites used in this experiment are presented in Table 1.

\section{Degree-of-conversion and Knoop microhardness analyses}

A total of 45 samples $(n=5)$ were prepared for degree of conversion and Knoop microhardness analyses. Experimental groups were divided according to composite (Z250, SDR, and NDU) and increment thickness (1, 1.5, and $3 \mathrm{~mm}$ ). Samples were obtained through single-increment composite placement into individualized cylindrical polytetrafluoroethylene matrices of $1,1.5$, and $3 \mathrm{~mm}$ height, with a center hole $2 \mathrm{~mm}$ in diameter. A polyester strip was placed on a polytetrafluoroethylene matrix, and above it a $500 \mathrm{~g}$ load was positioned for 5 seconds. Composites were light-cured by a polywave light-emitting-diode curing unit (Valo; Ultradent Products, South Jordan, UT, USA) in standard mode: 1,000 $\mathrm{mW} / \mathrm{cm}^{2}$ for 20 seconds. The curing unit was positioned directly over the polyester strip. It is worth noting that before experiments began, the light optical power $(\mathrm{mW})$ delivered

Table I Evaluated composites and respective manufacturer information

\begin{tabular}{|c|c|c|c|c|c|c|}
\hline & Manufacturer & Lot number & Matrix composition & Filler type & $\begin{array}{l}\text { Filler } \\
\text { content } \\
\text { (volume \%) }\end{array}$ & Shade \\
\hline Filtek Z250 & $\begin{array}{l}\text { 3M, St Paul, MN, } \\
\text { USA }\end{array}$ & 37,277 & $\begin{array}{l}\text { bis-GMA, bis-EMA, } \\
\text { UDMA }\end{array}$ & Zirconia/silica & 60 & $\mathrm{~A} 2$ \\
\hline $\begin{array}{l}\text { SureFil SDR } \\
\text { Flow }\end{array}$ & $\begin{array}{l}\text { Dentsply Caulk, } \\
\text { Milford, DE, USA }\end{array}$ & $65 I, 073 E$ & $\begin{array}{l}\text { Modified UDMA, } \\
\text { TEGDMA, EBPDMA }\end{array}$ & $\begin{array}{l}\text { Barium- } \\
\text { aluminofluoroborosilicate } \\
\text { glass, strontium- } \\
\text { aluminofluoroborosilicate glass }\end{array}$ & 44 & Universal \\
\hline N'Durance & $\begin{array}{l}\text { Septodont, Saint- } \\
\text { Maur-des-Fossés, } \\
\text { France }\end{array}$ & $020,7 \mid 3 A$ & $\begin{array}{l}\text { Bis-GMA, DDCDMA, } \\
\text { EBPDMA, UDMA }\end{array}$ & $\begin{array}{l}\text { Ytterbium fluoride nanoparticles } \\
\text { and nanoclusters, barium glass, } \\
\text { silica }\end{array}$ & 65 & A2 \\
\hline
\end{tabular}

Note: Data provided by manufacturers.

Abbreviations: bis-EMA, ethoxylated bisphenol A dimethacrylate; bis-GMA, bisphenol A diglycidyl ether dimethacrylate; DDCDMA, dimer dicarbamate dimethacrylate; EBPDMA, ethoxylated bisphenol A dimethacrylate; TEGDMA, triethylene glycol dimethacrylate; UDMA, urethane dimethacrylate. 
by the curing unit was measured using a power meter (Ophir Optronics, Jerusalem, Israel). The tip diameter was measured with a digital caliper (Mitutoyo, Tokyo, Japan) and the tip area determined in square centimeters. Irradiance $\left(\mathrm{mW} / \mathrm{cm}^{2}\right)$ was calculated by dividing the optical power by tip area.

The degree of conversion of sample-bottom surfaces was evaluated by Fourier-transform infrared spectroscopy. ${ }^{22}$ Absorption spectra of cured and uncured composite were recorded with a PerkinElmer Spectrum 100 spectrometer associated with a universal ATR sampling accessory (PerkinElmer, Waltham, MA, USA) with 16 scans at $4 \mathrm{~cm}^{-1}$ resolution using a baseline technique, ${ }^{22}$ based on the bands $1,638 \mathrm{~cm}^{-1}$ (aliphatic $\mathrm{C}=\mathrm{C}$ bonds) and $1,608 \mathrm{~cm}^{-1}$ (aromatic component group) as internal standard. The degree of conversion was calculated according to DC $(\%)=[1-(\mathrm{R}$ polymer/R monomer)] $\times 100$, where $\mathrm{R}$ represents the ratio between aliphatic band absorption at $1,640 \mathrm{~cm}^{-1}$ and aromatic band absorption at $1,610 \mathrm{~cm}^{-1}$, respectively. For microhardness determination, the same samples were assessed with a microhardness tester (HMV 2000; Shimadzu, Kyoto, Japan). A Knoop diamond indenter was used to apply a static load of $10 \mathrm{~g}$ for 10 seconds on top and bottom surfaces. For each sample and surface, the averages of five indentations were used in statistical analysis. ${ }^{23}$

\section{Polymerization-shrinkage stress: photoelastic analysis}

A model jaw maxillary second premolar (Manequins Odontológicos Marília, Marília, SP, Brazil) presenting a standard class I cavity ( $3 \mathrm{~mm}$ depth) was subjected to 45 dual impressions using polyvinyl siloxane in light and heavy consistencies (Express XT; 3M, St Paul, MN, USA). The impressions were poured with photoelastic resin (flexible GIV; Polipox, Cesário Lange, SP, Brazil), generating 45 replicas that were divided into nine groups $(\mathrm{n}=5)$, according to composite and restoration technique (applied in bulk, applied in two horizontal increments of $1.5 \mathrm{~mm}$ or applied in three horizontal increments of $1 \mathrm{~mm}$ ): group 1, Z250 bulk; group 2, two Z250 increments; group 3, three Z250 increments; group 4, SDR bulk; group 5, two SDR increments; group 6, three SDR increments; group 7, NDU bulk; group 8, two NDU increments; group 9, three NDU increments.

Replicas were stored at $37^{\circ} \mathrm{C}$ for 24 hours to allow stress relief and complete polymerization of photoelastic resin. Before restoration, the photoelastic replicas were placed between polarizing filters to verify residual stress, and when detected they were stored at $37^{\circ} \mathrm{C}$ for a further 24 hours until total stress release (Figure 1).

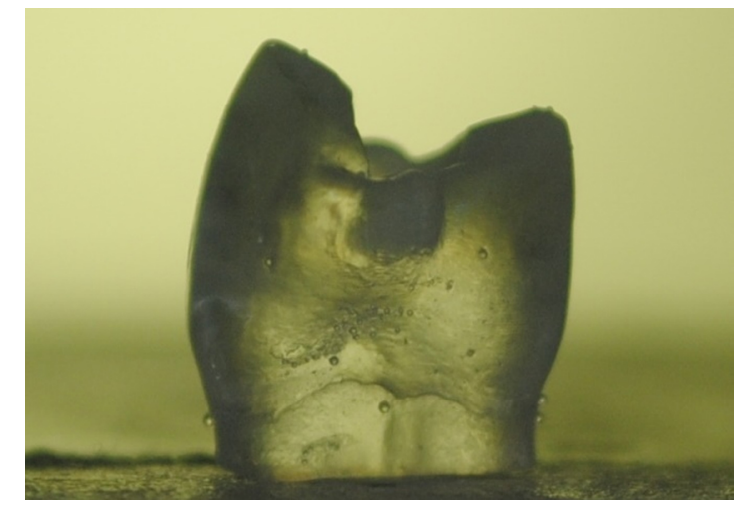

Figure I Initial image of photoelastic replica without stress.

Internal cavity surfaces were sandblasted with $50 \mu \mathrm{m}$ aluminum oxide particles (BioArt, São Carlos, SP, Brazil) to improve adhesion. An adhesive layer of Adper Single Bond 2 (3M) was applied on the surfaces following manufacturer's instructions and light-cured for 20 seconds. Each composite was inserted into the cavity according to restoration techniques: a $3 \mathrm{~mm}$ increment was applied in bulk, and three horizontal increments of $1 \mathrm{~mm}$ or two horizontal increments of $1.5 \mathrm{~mm}$. In both techniques, each increment was light-cured by the polywave light-emitting-diode curing unit in standard mode $-1,000 \mathrm{~mW} / \mathrm{cm}^{2}$ for 20 seconds $(20$ $\mathrm{J} / \mathrm{cm}^{2}$ ) - positioned directly over the occlusal surface. The light irradiance of the curing unit was checked again with a power meter to ensure constant light intensity.

Photoelastic analysis was performed immediately and at 24 hours after composite curing. Samples were examined with transmission polariscopy (PTH-A-01; Federal University of Uberlândia, Uberlândia, MG, Brazil), in which they were placed between two polarizing lenses over a white-light source, with $90^{\circ}$ filter angulation. Constant isochromatic photoelastic fringes were obtained and images recorded with a 10.2-megapixel digital camera (D3000; Nikon, Tokyo, Japan). An isochromatic fringe-order pattern, which points out increasing stress - from 0 (black fringe) to 4 (pink-green transition fringe) - was used for scoring (Table 2). ${ }^{24}$ Shrinkage stress was qualitatively analyzed, dividing the fringe images into seven areas (Figure 2). Each area was scored 0-4 according to level of stress, comparing the obtained fringes to the fringe-order pattern. ${ }^{25}$

\section{Statistical analyses}

Statistical analyses were performed using SPSS 21.0 (IBM, Armonk, NY, USA). Shapiro-Wilk and KolmogorovSmirnov tests were performed to check the results' normality 
regarding the degree of conversion and microhardness analyses $(P>0.05)$. Both results were subjected to two-way ANOVA and Bonferroni post hoc testing $(\alpha=0.05)$. Shrinkage-stress results were subjected to a nonparametric test (Mann-Whitney $U$ ) and pairwise comparison $(\alpha=0.05)$. Composites and

Table 2 Isochromatic fringe-order pattern according to color change

\begin{tabular}{|l|l|}
\hline Fringe color & Fringe order $(\mathbf{N})$ \\
\hline Black & 0 \\
\hline Gray & 0.28 \\
White & 0.45 \\
Pale yellow & 0.60 \\
Orange & 0.79 \\
Dull red & 0.90 \\
\hline Red-blue transition (purple) & 1 \\
\hline Deep blue & 1.06 \\
Blue-green & 1.20 \\
Green-yellow & 1.38 \\
Orange & 1.62 \\
Rose red & 1.81 \\
\hline Red-green transition (purple) & 2 \\
\hline Green & 2.33 \\
Green-yellow & 2.50 \\
Red & 2.67 \\
\hline Red-green transition & 3 \\
\hline Green & 3.10 \\
Pink & 3.60 \\
\hline Pink-green transition & 4 \\
\hline
\end{tabular}

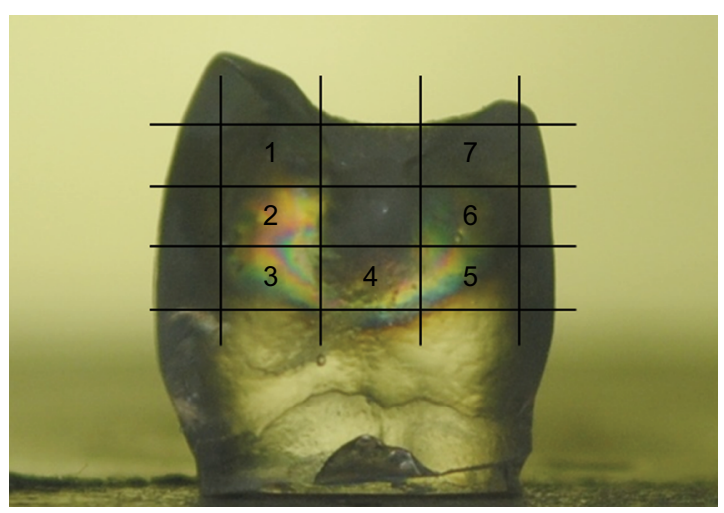

Figure 2 Fringes of polymerization-shrinkage stress divided in areas. number/thicknesses of increment were evaluated one by one for each area.

\section{Results \\ Degree of conversion}

Results of degree-of-conversion testing are shown in Table 3. Regardless of increment thickness, SDR presented the highest degree of conversion, while Z250 and NDU showed the lowest $(P<0.0001)$. Z250 presented a higher degree of conversion in $1 \mathrm{~mm}$ increments than in $3 \mathrm{~mm}$ increments $(P<0.004)$; however the degree of conversion in $1.5 \mathrm{~mm}$ increments was statically similar to that in 1 and $3 \mathrm{~mm}$ increments. For NDU, degree of conversion was lower in increments of $3 \mathrm{~mm}(P<0.025)$. SDR was the only composite that did not present statistically significant variation in degree of conversion between any increments.

\section{Knoop microhardness}

Table 4 shows microhardness results of top and bottom surfaces. For composites on both top and bottom surfaces, Z250 presented the highest values for microhardness, while SDR and NDU presented the lowest ones $(P<0.018)$. Top-surface microhardness of $1.5 \mathrm{~mm}$ increments was intermediate for NDU and lower for SDR $(P<0.009)$. For all other thickness increments, SDR and NDU presented statistically similar values.

For all composites, microhardness on top surfaces did not differ significantly between any increments. On the bottom surface, on the other hand, Z250 showed higher microhardness in $1 \mathrm{~mm}$ increments than $3 \mathrm{~mm}$ increments $(P<0.027)$. The microhardness of $1.5 \mathrm{~mm}$ increments was statistically similar to that of 1 and $3 \mathrm{~mm}$ increments. Bottom-surface microhardness of SDR and NDU did not differ significantly between increments of 1, 1.5, and $3 \mathrm{~mm}$. Z250 and NDU showed statistical differences between top- and bottomsurface microhardness of 1.5 and $3 \mathrm{~mm}$ increments. Top surfaces showed higher values for microhardness than bottom surfaces $(P<0.042)$. SDR was the only composite that showed no difference between top and bottom surfaces for any increment thickness.

Table 3 Mean (SD) degree of conversion (\%) of composites in different increment thicknesses

\begin{tabular}{|l|l|l|l|l|}
\hline & I $\mathbf{~ m m}$ & I.5 $\mathbf{~ m m}$ & $\mathbf{3} \mathbf{~ m m}$ & $P$-value \\
\hline Filtek Z250 & $44.9 I(6.42) \mathrm{Ab}$ & $40.87(0.4 \mathrm{I}) \mathrm{ABb}$ & $34.32(5.75) \mathrm{Bb}$ & $P=0.004$ \\
SureFil SDR Flow & $59.34(\mathrm{I} .69) \mathrm{Aa}$ & $58.2 \mathrm{I}(0.72) \mathrm{Aa}$ & $57.1 \mathrm{I}(2.12) \mathrm{Aa}$ & \\
N'Durance & $39.68(\mathrm{I} .20) \mathrm{Ab}$ & $37.90(6.37) \mathrm{Ab}$ & $30.00(\mathrm{II} .79) \mathrm{Bb}$ & $P=0.008$ \\
$P$-value & $P=0.00 \mathrm{I}$ & $P=0.00 \mathrm{I}$ & $P=0.00 \mathrm{I}$ & \\
\hline
\end{tabular}

Notes: Means followed by distinct letters (uppercase in horizontal and lowercase in vertical comparison) differ from each other ( $P \leq 0.05)$. 


\section{Polymerization-shrinkage stress}

After qualitative analyses of areas, common shrinkage-stress behavior was observed between areas 1 and 7,2 and 6, and 3 and 5 . As such, the results of these areas were merged. There was no difference in shrinkage-stress rate between samples analyzed immediately and at 24 hours after light-curing either. Table 5 presents polymerization-shrinkage-stress results for all areas and thickness of increments. Analysis of areas 1 and 7 revealed no statistical difference between shrinkage stress of composites, regardless of number/ thickness of increments. SDR presented higher stress when handled with one increment of $3 \mathrm{~mm}$ and lower stress when handled with three increments of $1 \mathrm{~mm}(P=0.016)$. Stress generated with two increments of $1.5 \mathrm{~mm}$ was statistically similar to stress generated with one increment of $3 \mathrm{~mm}$ and three increments of $1 \mathrm{~mm}$. Neither Z250 nor NDU shrinkage stresses differed statistically between number/thickness of increments.
In areas 2 and 6, all composites presented statistically similar values of shrinkage stress when handled with one increment of $3 \mathrm{~mm}$. When handled with two increments of $1.5 \mathrm{~mm}$, however, Z250 showed higher stress than SDR $(P=0.008)$. NDU shrinkage stress did not differ from Z250 or SDR. When handled with three increments of $1 \mathrm{~mm}$, NDU presented higher stress than SDR $(P=0.008)$. Z250 shrinkage stress did not differ statistically from shrinkage stresses of NDU and SDR. Shrinkage stresses of Z250 and SDR did not differ statistically between number/thicknesses of increments. NDU presented higher stress when handled with three increments of $1 \mathrm{~mm}$ and lower stress when handled with one increment of $3 \mathrm{~mm}(P=0.008)$. Shrinkage stress of two increments of $1.5 \mathrm{~mm}$ of NDU was statistically similar to shrinkage stresses of one increment of $3 \mathrm{~mm}$ and three increments of $1 \mathrm{~mm}$.

In areas 3 and 5, all composites presented statistical similar values of shrinkage stress when handled with one

Table 4 Mean (SD) Knoop microhardness of top and bottom surfaces of composites in different increment thicknesses

\begin{tabular}{|c|c|c|c|c|c|}
\hline & Composite & I mm & $1.5 \mathrm{~mm}$ & $3 \mathrm{~mm}$ & $P$-value \\
\hline \multirow[t]{2}{*}{ Top } & $\begin{array}{l}\text { Filtek Z250 } \\
\text { SureFil SDR Flow } \\
\text { N'Durance } \\
\end{array}$ & $\begin{array}{l}52.45(\mathrm{I} 6.5 \mathrm{I}) \mathrm{Aa} \\
\mathrm{I} 7.10(\mathrm{I} .48) \mathrm{Ab} \\
24.20(\mathrm{I} .87) \mathrm{Ab} \\
\end{array}$ & $\begin{array}{l}51.31(15.83) \mathrm{Aa} \\
17.78(0.39) \mathrm{Ac} \\
31.64(9.65) \mathrm{Ab} \\
\end{array}$ & $\begin{array}{l}52.71(12.85) \mathrm{Aa} \\
19.88(2.14) \mathrm{Ab} \\
29.16(7.93) \mathrm{Ab} \\
\end{array}$ & \\
\hline & $P$-value & $P=0.001$ & $P=0.009$ & $P=0.001$ & \\
\hline \multirow[t]{2}{*}{ Bottom } & $\begin{array}{l}\text { Filtek Z250 } \\
\text { SureFil SDR Flow } \\
\text { N'Durance }\end{array}$ & $\begin{array}{l}42.60(\mathrm{II} .85) \mathrm{Aa} \\
\mathrm{I} 5.66(\mathrm{I} .5 \mathrm{I}) \mathrm{Ab} \\
22.56(4.87) \mathrm{Ab}\end{array}$ & $\begin{array}{l}40.68(8.6 \mathrm{I}) \mathrm{ABa}^{*}(P=0.042) \\
\mathrm{I} 6.0 \mathrm{I}(0.4 \mathrm{I}) \mathrm{Ab} \\
20.48(2.86) \mathrm{Ab}^{*}(P=0.034)\end{array}$ & $\begin{array}{l}30.94(9.22) \mathrm{Ba}^{*}(P=0.00 \mathrm{I}) \\
\mathrm{I} 7.42(0.82) \mathrm{Ab} \\
\mathrm{I} 8.5 \mathrm{I}(2.00) \mathrm{Ab}^{*}(P=0.042)\end{array}$ & $P=0.027$ \\
\hline & $P$-value & $P=0.001$ & $P=0.001$ & $P=0.018$ & \\
\hline
\end{tabular}

Notes: Means followed by distinct letters (uppercase in horizontal and lowercase in vertical comparison) differ from each other ( $P \leq 0.05)$. $*$ Presented lower microhardness than top surface.

Table 5 Fringe-order polymerization-shrinkage stress of composites areas of different thickness

\begin{tabular}{|c|c|c|c|c|c|}
\hline \multirow{2}{*}{$\begin{array}{l}\text { Comparison } \\
\text { areas }\end{array}$} & \multirow[t]{2}{*}{ Composite } & \multicolumn{3}{|c|}{ Median fringe order (range) } & \multirow[b]{2}{*}{$P$-value } \\
\hline & & $\mathrm{I} / 3 \mathrm{~mm}$ & $2 / 1.5 \mathrm{~mm}$ & $3 / 1 \mathrm{~mm}$ & \\
\hline I and 7 & $\begin{array}{l}\text { Filtek Z250 } \\
\text { SureFil SDR Flow } \\
\text { N'Durance }\end{array}$ & $\begin{array}{l}0.79(0.60-1.62) \mathrm{Aa} \\
0.60(0.60-1.38) \mathrm{Aa} \\
0.60(0-0.79) \mathrm{Aa}\end{array}$ & $\begin{array}{l}0.38(0-0.79) \mathrm{Aa} \\
0.60(0.28-0.79) \mathrm{ABa} \\
0.79(0.28-1.62) \mathrm{Aa}\end{array}$ & $\begin{array}{l}0.60(0-1.38) \mathrm{Aa} \\
0.45(0-0.60) \mathrm{Ba} \\
0.60(0-0.79) \mathrm{Aa}\end{array}$ & $P=0.016$ \\
\hline 2 and 6 & $\begin{array}{l}\text { Filtek Z250 } \\
\text { SureFil SDR Flow } \\
\text { N'Durance } \\
P \text {-value }\end{array}$ & $\begin{array}{l}\mathrm{I} .8 \mathrm{I}(0.60-2.67) \mathrm{Aa} \\
\mathrm{I} .20(0.90-2.00) \mathrm{Aa} \\
0.79(0.60-1.20) \mathrm{Ba}\end{array}$ & $\begin{array}{l}\mathrm{I} .6 \mathrm{I}(\mathrm{I} .20-3.60) \mathrm{Aa} \\
\mathrm{I} .00(0.79-1.20) \mathrm{Ab} \\
\mathrm{I} .20(0.79-1.8 \mathrm{I}) \mathrm{ABab} \\
P=0.008\end{array}$ & $\begin{array}{l}0.90(0.79-2.33) \mathrm{Aab} \\
0.90(0.45-1.20) \mathrm{Ab} \\
\mathrm{I} .8 \mathrm{I}(1.38-3.60) \mathrm{Aa} \\
P=0.008\end{array}$ & $P=0.008$ \\
\hline 3 and 5 & $\begin{array}{l}\text { Filtek Z250 } \\
\text { SureFil SDR Flow } \\
\text { N'Durance } \\
P \text {-value }\end{array}$ & $\begin{array}{l}0.79(0.45-1.20) \mathrm{Aa} \\
0.90(0.60-1.20) \mathrm{Aa} \\
0.79(0.45-1.10) \mathrm{Ba}\end{array}$ & $\begin{array}{l}1.20(0.79-2.20) \mathrm{Aa} \\
0.79(0.45-1.20) \mathrm{Aa} \\
0.79(0.60-1.8 \mathrm{I}) \mathrm{ABa}\end{array}$ & $\begin{array}{l}0.60(0.60-2.20) \mathrm{Aab} \\
0.79(0.28-1.10) \mathrm{Ab} \\
1.20(1.10-1.8 \mathrm{I}) \mathrm{Aa} \\
P=0.016\end{array}$ & $P=0.016$ \\
\hline 4 & $\begin{array}{l}\text { Filtek Z250 } \\
\text { SureFil SDR Flow } \\
\text { N'Durance }\end{array}$ & $\begin{array}{l}0.79(0.60-1.38) \mathrm{Aa} \\
0.90(0.79-I .10) \mathrm{Aa} \\
0.79(0.28-0.79) \mathrm{Aa}\end{array}$ & $\begin{array}{l}0.90(0.60-1.38) \mathrm{Aa} \\
0.79(0.60-0.90) \mathrm{Aa} \\
0.79(0.60-1.20) \mathrm{Aa}\end{array}$ & $\begin{array}{l}0.60(0.28-0.79) \mathrm{Aa} \\
0.79(0.60-0.90) \mathrm{Aa} \\
0.79(0-1.06) \mathrm{Aa}\end{array}$ & \\
\hline
\end{tabular}

Notes: Medians followed by distinct letters (uppercase in horizontal and lowercase in vertical comparison) differ from each other ( $P \leq 0.05)$. Statistical analyses confined to corresponding areas of comparison. 
increment of $3 \mathrm{~mm}$ and two increments of $1.5 \mathrm{~mm}$. When handled with three increments of $1 \mathrm{~mm}$, NDU showed higher stress than SDR $(P=0.016)$. Shrinkage stress of Z250 did not differ statistically from shrinkage stress of NDU or SDR. Shrinkage stresses of Z250 and SDR did not differ statistically between number/thickness of increments. NDU presented higher stress when handled with three increments of $1 \mathrm{~mm}$ and lower stress when handled with one increment of $3 \mathrm{~mm}(P=0.016)$. Shrinkage stress of two increments of $1.5 \mathrm{~mm}$ of NDU was statistically similar to shrinkage stress of one increment of $3 \mathrm{~mm}$ and three increments of $1 \mathrm{~mm}$. In area 4 , there was no statistical difference among shrinkage stress of composites, regardless of number/thicknesses of increments. Likewise, no composite presented statistical difference in shrinkage stress between number/thickness of increments (Figure 3).

\section{Discussion}

This study aimed to evaluate the degree of conversion, Knoop microhardness, and polymerization-shrinkage stress by photoelasticity of three dental composites - a microhybrid (Z250), a bulk-fill flowable (SDR), and a nanohybrid composite (NDU) - submitted to different increment thickness. Both null hypotheses, that thickness of increment would not affect tested properties and that there would not be significant differences in tested properties among composites, were rejected. The highest values for degree of conversion were obtained by SDR, regardless of increment thickness, which is in accordance with previous studies. ${ }^{26,27}$ SDR presents a photoinitiator group, a modulator of polymerization reaction in urethane dimethacrylate (UDMA). The polymerization modulator reacts with camphorquinone, leading to formation of polymers with low elastic modulus and decreased
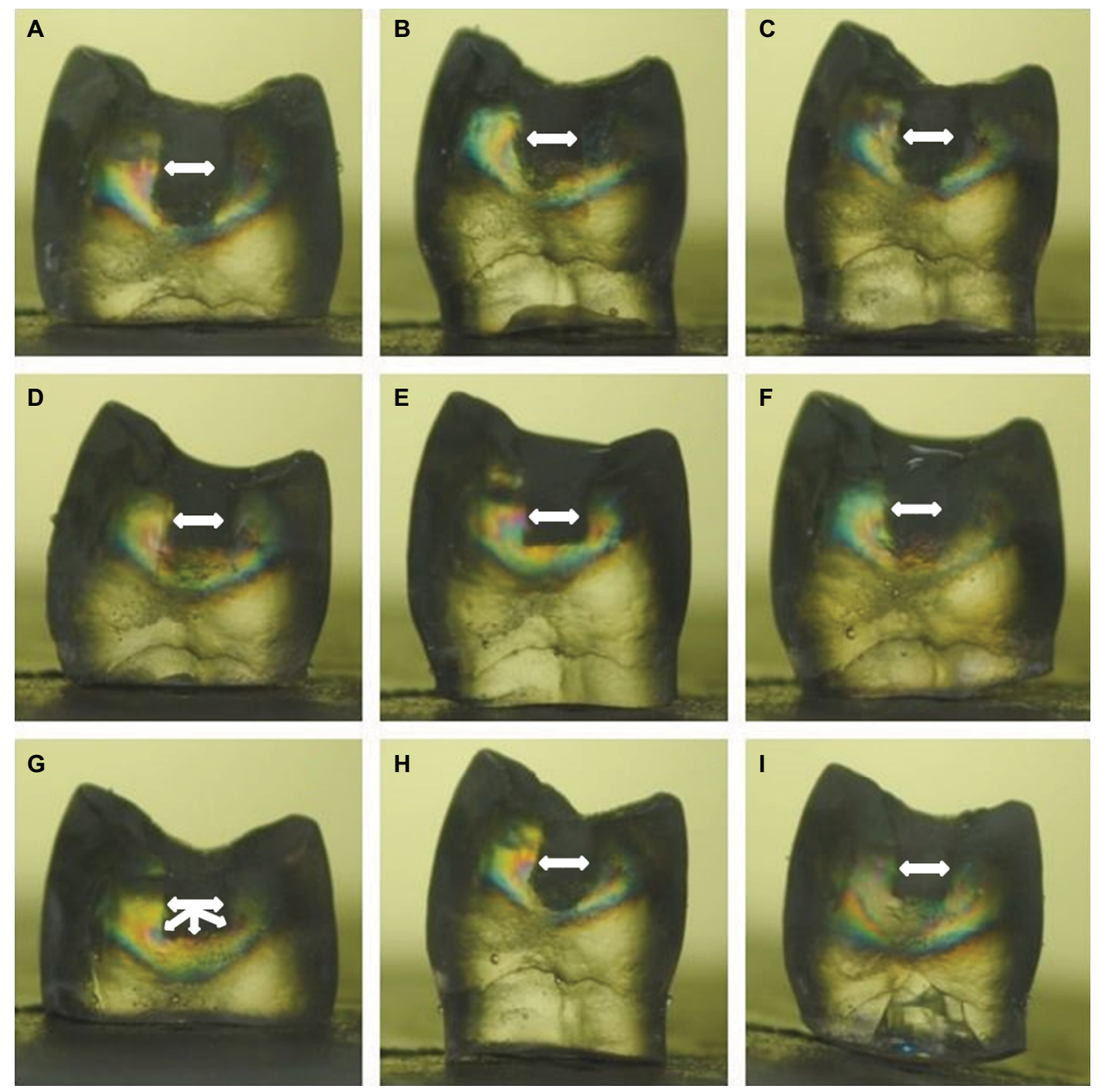

Figure 3 Representative images of polymerization-shrinkage stress obtained by each group.

Notes: (A) Obtained by Z250 bulk; (B) obtained by two Z250 increments; (C) obtained by three Z250 increments; (D) obtained by SDR bulk; (E) obtained by two SDR increments; (F) obtained by three SDR increments; (G) obtained by NDU bulk; (H) obtained by two NDU increments; (I) obtained by three NDU increments. Arrows indicate the location of higher numerical values. 
polymerization stress, ${ }^{10,28,29}$ thus enabling the placement of composite in increments of up to $4 \mathrm{~mm},{ }^{30}$ as demonstrated in the results. The presence of amino groups (NH) in the urethane structure of UDMA is responsible for characteristic chain-transfer reactions, which provide an alternative way for further polymerization. These reactions result in increased mobility of radical sites in the network, and thus improve polymerization and conversion of monomer. ${ }^{31}$ Indeed, interestingly, SDR was the only composite that did not present statistically significant variations in degree of conversion between any increments.

Despite the results obtained for degree of conversion, SDR presents low filler content (44\% in volume) associated with prepolymerized particles $s^{30,31}$ and development of more linear polymer chains, due to slower polymerization reaction. ${ }^{32}$ This feature led the composite in general to obtain lower microhardness values than the other composites. Similar findings were obtained by Alshali et al, who remarked that Z250 presented higher values of microhardness than SDR. ${ }^{33}$ It is worth noting, however, that SDR was the only composite that did not show a difference in microhardness values between top and bottom surfaces for any increment thickness, and showed microhardness on top and bottom surfaces similar to NDU in all increment thicknesses, except for $1.5 \mathrm{~mm}$ on the top surface. These findings demonstrate the effectiveness of this composite to be uniformly polymerized in increments up to $3 \mathrm{~mm}$ with no reduction of its physical properties.

In this context, the composites shades should be considered. SDR presents translucent universal color, while Z250 and NDU are of A2 shade. One may state that polymerization of resinous materials is correlated with light transmission and scattering. ${ }^{3,10,34}$ Namely, considering material's translucency, the more translucent the composite, the more effective the composite's polymerization. ${ }^{34,35}$ It should be highlighted, however, that not only the shade of composite interferes in translucency property but also its thickness, type, amount, and filler-size content, as well as refraction indices between fillers and matrix resin..$^{35}$ Therefore, the results for SDR, though showing correlations with shade, are consequence of several factors. Surely, further studies including analysis of composites' different colors as an influence in their properties must be considered.

The presence of a dimer acid-based monomer of high molecular weight in NDU may slow the reaction and favor the development of more linear polymers as well. ${ }^{32,36}$ Accordingly, even though the composite has high filler content $(65 \%$ in volume), the development of linear polymers may have resulted in lower microhardness values than Z250 on both top and bottom surfaces. As elucidated by Ilie and Hickel, the relatively low cross-link density of dimer acid-based dimethacrylates favors the production of polymers with high flexibility but low modulus of elasticity. ${ }^{37}$ Indeed, though the current literature provides few data concerning the microhardness of NDU, ${ }^{38}$ studies have suggested that composites formulated with dimer acid-based monomers present low mechanical properties. ${ }^{39,40}$

Herein, one may observe that NDU showed a lower degree of conversion than SDR, with lowest values in $3 \mathrm{~mm}$ increments. Studies have revealed great degree of conversion values for NDU, especially at higher depths. ${ }^{38-40}$ Nevertheless, the presence of a high-molecular-weight monomer should be considered. As well stated by two studies, highmolecular-weight monomers in general present lower mobility during polymerization, thus reducing the final degree of conversion. $^{41,42}$

According to the manufacturer, Z250 also has highmolecular-weight monomers (bisphenol A diglycidyl ether dimethacrylate, ethoxylated bisphenol A dimethacrylate, and urethane dimethacrylate) associated with high filler content (60\% in volume). Although its filler content is slightly lower than that of NDU, the presence of zirconia filler may have influenced the microhardness results. Also, the development of polymers with higher cross-linking may increase composite elastic modulus and thus enhance surface microhardness. Nevertheless, the speed of reaction may increase cross-link density, but shorten the vitrification period of the composite, thereby reducing the degree of conversion. ${ }^{36}$

Based on polymerization-shrinkage stress (Table 5), it is evident that the pattern of stress development in a class I cavity is variable. When bulk filling was performed, stress was similar among composites in all areas. When composites were applied in two horizontal increments of $1.5 \mathrm{~mm}$, stress was similar among composites in five of seven analyzed areas. In areas 2 and 6, Z250 stress was higher than that of SDR. When composites were applied in three increments of $1 \mathrm{~mm}$, on the other hand, stress was similar among composites in only three areas. In areas 2, 3, 5, and 6, NDU showed higher stress than SDR. Although shrinkage in a light-curing composite is assumed to be directed toward the light source, ${ }^{43}$ the literature has not established a pattern of stress developed from this shrinkage. The results of this study suggest that the stress of each composite is developed in a different direction along the entire cavity, and may depend on composite composition, curing unit, restoration technique, and procedure accuracy.

Clearly, the polymerization efficiency of SDR is notable. The composite showed no statistical difference between 
shrinkage stress developed from any restoration technique in five analyzed areas. Furthermore, when composites were applied in horizontal increments, in two areas SDR presented lower shrinkage stress than Z250 in $1.5 \mathrm{~mm}$ increments. Compared to NDU, SDR presented in four areas lower shrinkage stress in $3 \mathrm{~mm}$ increments. However, lower shrinkage stress of this composite was expected, mainly when greater increments were placed into the cavity. The results showed that in general, SDR performed as well as the other composites when inserted into a cavity with high $\mathrm{C}$ factor. Equally important, in areas 1 and 7, shrinkage stress of SDR was higher when it was applied in bulk than when it was applied in three increments of $1 \mathrm{~mm}$. An explanation could rely on the fact that all composites shrink in direction to the light source during polymerization. ${ }^{43}$ Considering areas 1 and 7 were closest to the light source, shrinkage stress could have concentrated more at this point in the case of bulk filling. One may observe, however, that despite presenting higher stress when bulk-applied, in the same areas SDR shrinkage stress in this restoration technique did not differ from Z250 or NDU shrinkage stress.

The behavior of NDU regarding shrinkage stress must be addressed as well. The composite showed no statistical difference between shrinkage stress developed from any restoration technique in three analyzed areas. Nevertheless, in areas 2, 3, 5, and 6, NDU showed lower stress when applied in bulk than handled with three increments of $1 \mathrm{~mm}$. Also, in this last case, the stress generated by NDU was statistically higher than the stress generated by the other composites. Apparently, shrinkage stress developed by NDU is somehow more homogeneous when the composite is applied in bulk. Evidence of this is given in Figure 3, which shows that NDU was the only composite that presented the same numerical values of shrinkage stress in areas 2, 3, 5, and 6. NDU is considered a low-polymerization-shrinkage material, due to its high filler content and presence of dimer acid derived from dimethacrylate. ${ }^{37,44,45}$ The presence of dimer acidbased monomer of high molecular weight with lower initial concentration of double bonds and relatively low viscosity provides less polymerization shrinkage. ${ }^{37-40}$ In addition, as already stated, its relatively low density of cross-linking can produce polymers with high flexibility and low modulus of elasticity. ${ }^{37,44}$

However, it should be highlighted that when composites were applied in bulk, all presented statistical similar values for shrinkage stress, irrespective of analyzed areas. This was expected from SDR, but not from conventional composites. Surprisingly, Z250 showed no statistical difference in shrinkage stress developed from any restoration technique, which might indicate that this composite presents homogeneous behavior in shrinkage-stress development. One may consider, however, that as Z250 and NDU are not bulk-fill composites, the bottom surfaces of largest increments are less polymerized in these materials, as demonstrated in the results for degree of conversion, ie, the reaction proceeds more slowly, generating a layer with low elastic modulus. This also may have relieved polymerization-shrinkage stress developed in the top surface, thus providing similar results among composites. ${ }^{46}$ This condition, however, could clinically result in premature failure of the restoration, due to fracture or hypersensitivity.

\section{Conclusion}

Within the limitations imposed by this in vitro study, it can be concluded that the investigated bulk-fill composite (SDR) demonstrated a generally better degree of conversion and similar microhardness and incidence of polymerizationshrinkage stress in deeper layers when compared to conventional composites (Z250 and NDU). Findings suggest that bulk-fill composites may perform as well as conventional nanohybrid and microhybrid composites. However, although bulk-fill composites are indicated for single placement, considering the importance of reducing shrinkage stress, incremental filling technique might be beneficial, irrespective of composite type.

\section{Acknowledgments}

This work was supported by the State of São Paulo Research Foundation (FAPESP; 2014/02707-7). The authors are grateful to Dr Núbia Inocencya Pavesi Pini for her technical assistance.

\section{Disclosure}

The authors report no conflicts of interest in this work.

\section{References}

1. Rueggeberg FA. From vulcanite to vinyl, a history of resins in restorative dentistry. J Prosthet Dent. 2002;87(4):364-379.

2. Ferracane JL. Resin composite — state of the art. Dent Mater. 2011;27(1): 29-38.

3. Alqahtani MQ, Michaud PL, Sullivan B, Labrie D, Alshaafi MM, Price RB. Effect of high irradiance on depth of cure of a conventional and a bulk fill resin-based composite. Oper Dent. 2015;40(6):662-672.

4. Aguiar FH, Andrade KR, Leite Lima DA, Ambrosano GM, Lovadino JR. Influence of light curing and sample thickness on microhardness of a composite resin. Clin Cosmet Investig Dent. 2009;1:21-25.

5. Calheiros FC, Braga RR, Kawano Y, Ballester RY. Relationship between contraction stress and degree of conversion in restorative composites. Dent Mater. 2004;20(10):939-946.

6. Ferracane JL, Hilton TJ. Polymerization stress - is it clinically meaningful? Dent Mater. 2016;32(1):1-10. 
7. Park J, Chang J, Ferracane J, Lee IB. How should composite be layered to reduce shrinkage stress: incremental or bulk filling? Dent Mater. 2008;24(11):1501-1505

8. Yap AU. Effectiveness of polymerization in composite restoratives claiming bulk placement: impact of cavity depth and exposure time. Oper Dent. 2000;25(2):113-120.

9. Emami N, Söderholm KJ. How light irradiance and curing time affect monomer conversion in light-cured resin composites. Eur J Oral Sci. 2003;111(6):536-542.

10. Fronza BM, Ayres A, Pacheco RR, Rueggeberg FA, Dias C, Giannini M. Characterization of inorganic filler content, mechanical properties, and light transmission of bulk-fill resin composites. Oper Dent. 2017;42(4):445-455.

11. Francis AV, Braxton AD, Ahmad W, Tantbirojn D, Simon JF, Versluis A. Cuspal flexure and extent of cure of a bulk-fill flowable base composite. Oper Dent. 2015;40(5):515-523.

12. Furness A, Tadros MY, Looney SW, Rueggeberg FA. Effect of bulk/ incremental fill on internal gap formation of bulk-fill composites. $J$ Dent. 2014;42(4):439-449.

13. Fronza BM, Rueggeberg FA, Braga RR, et al. Monomer conversion, microhardness, internal marginal adaptation, and shrinkage stress of bulk-fill resin composites. Dent Mater. 2015;31(12):1542-1551.

14. Leprince JG, Palin WM, Vanacker J, Sabbagh J, Devaux J, Leloup G. Physico-mechanical characteristics of commercially available bulk-fill composites. J Dent. 2014;42(8):993-1000.

15. Rosatto CM, Bicalho AA, Veríssimo C, et al. Mechanical properties, shrinkage stress, cuspal strain and fracture resistance of molars restored with bulk-fill composites and incremental filling technique. $J$ Dent 2015;43(12):1519-1528.

16. El-Damanhoury H, Platt J. Polymerization shrinkage stress kinetics and related properties of bulk-fill resin composites. Oper Dent. 2014;39(4):374-382.

17. Al Sunbul H, Silikas N, Watts DC. Polymerization shrinkage kinetics and shrinkage-stress in dental resin-composites. Dent Mater. 2016;32(8):998-1006.

18. Rullmann I, Schattenberg A, Marx M, Willershausen B, Ernst CP. Photoelastic determination of polymerization shrinkage stress in low-shrinkage resin composites. Schweiz Monatsschr Zahnmed. 2012;122(4):294-299.

19. Rullman I, Patyna M, Janssen B, Willershausen B, Ernst CP. Determination of polymerization shrinkage of different composites using a photoelastic method. Am J Dent. 2017;30(1):16-22.

20. Turcio KH, Goiato MC, Gennari Filho H, dos Santos DM. Photoelastic analysis of stress distribution in oral rehabilitation. J Craniofac Surg. 2009;20(2):471-474.

21. Pesqueira AA, Goiato MC, Filho HG, et al. Use of stress analysis methods to evaluate the biomechanics of oral rehabilitation with implants. $J$ Oral Implantol. 2014;40(2):217-228.

22. Rueggeberg FA, Hashinger DT, Fairhurst CW. Calibration of FTIR conversion analysis of contemporary dental resin composites. Dent Mater. 1990;6(4):241-249.

23. Giorgi MC, Aguiar FH, Soares LE, Martin AA, Liporoni PC, Paulillo LA. Does an additional UV LED improve the degree of conversion and Knoop Hardness of light-shade composite resins? Eur J Dent. 2012;6(4):396-401.

24. Çehreli S, Özçırpıcı AA, Yılmaz A. Tilted orthodontic micro implants: a photoelastic stress analysis. Eur J Orthod. 2013;35(5):563-567.

25. Yamamoto M, Miura H, Okada D, Komada W, Masuoka D. Photoelastic stress analysis of different post and core restoration methods. Dent Mater J. 2009;28(2):204-211.

26. Yokesh CA, Hemalatha P, Muthalagu M, Justin MR. Comparative evaluation of the depth of cure and degree of conversion of two bulk fill flowable composites. J Clin Diagn Res. 2017;11(8):ZC86-ZC89.
27. Jain L, Mehta D, Meena N, Gupta R. Influence of light energy density, composite type, composite thickness, and postcuring phase on degree of conversion of bulk-fill composites. Contemp Clin Dent. 2018;9(5):147-S152.

28. Giovannetti A, Goracci C, Vichi A, Chieffi N, Polimeni A, Ferrari M. Post retentive ability of a new resin composite with low stress behaviour. J Dent. 2012;40(4):322-328.

29. Hernandes NM, Catelan A, Soares GP, et al. Influence of flowable composite and restorative technique on microleakage of class II restorations. J Investig Clin Dent. 2014;5(4):283-288.

30. Jang JH, Park SH, Hwang IN. Polymerization shrinkage and depth of cure of bulk-fill resin composites and highly filled flowable resin. Oper Dent. 2015;40(2):172-180.

31. Alshali RZ, Silikas N, Satterthwaite JD. Degree of conversion of bulkfill compared to conventional resin-composites at two time intervals. Dent Mater. 2013;29(9):e213-e217.

32. Soares GP, Ambrosano GM, Lima DA, et al. Effect of light polymerization time, mode, and thermal and mechanical load cycling on microleakage in resin composite restorations. Lasers Med Sci. 2014;29(2):545-550.

33. Alshali RZ, Salim NA, Satterthwaite JD, Silikas N. Post-irradiation hardness development, chemical softening, and thermal stability of bulk-fill and conventional resin-composites. $J$ Dent. 2015;43(2):209-218.

34. Faria-E-Silva AL, Fanger C, Nguyen L, Howerton D, Pfeifer CS. Impact of material shade and distance from light curing unit tip on the depth of polymerization of composites. Braz Dent J. 2017;28(5):632-637.

35. Kim EH, Jung KH, Son SA, Hur B, Kwon YH, Park JK. Effect of resin thickness on the microhardness and optical properties of bulk-fill resin composites. Restor Dent Endod. 2015;40(2):128-135.

36. Odian G. Step polymerization. In: Principles of Polymerization. Hoboken: John Wiley \& Sons, Inc.; 2004:40-185.

37. Ilie N, Hickel R. Resin composite restorative materials. Aust Dent J. 2011;56(Suppl 1):59-66.

38. Czasch P, Ilie N. In vitro comparison of mechanical properties and degree of cure of a self-adhesive and four novel flowable composites. $J$ Adhes Dent. 2013;15(3):229-236.

39. Lu H, Trujillo-Lemon M, Ge J, Stansbury JW. Dental resins based on dimer acid dimethacrylates: a route to high conversion with low polymerization shrinkage. Compend Contin Educ Dent. 2010;31(Spec No 2):1-4.

40. Frauscher KE, Ilie N. Depth of cure and mechanical properties of nano-hybrid resin-based composites with novel and conventional matrix formulation. Clin Oral Investig. 2012;16(5):1425-1434.

41. Dewaele M, Truffier-Boutry D, Devaux J, Leloup G. Volume contraction in photocured dental resins: the shrinkage-conversion relationship revisited. Dent Mater. 2006;22(4):359-365.

42. Sideridou I, Tserki V, Papanastasiou G. Effect of chemical structure on degree of conversion in light-cured dimethacrylate-based dental resins. Biomaterials. 2002;23(8):1819-1829.

43. Chandrasekhar V, Rudrapati L, Badami V, Tummala M. Incremental techniques in direct composite restoration. J Conserv Dent. 2017;20(6):386-391.

44. Ilie N, Hickel R. Investigations on a methacrylate-based flowable composite based on the SDR technology. Dent Mater. 2011;27(4): 348-355.

45. Yamasaki LC, de Vito Moraes AG, Barros M, et al. Polymerization development of "low-shrink" resin composites: reaction kinetics, polymerization stress and quality of network. Dent Mater. 2013;29(9): e169-e179.

46. Aguiar FH, Ajudarte KF, Lovadino JR. Effect of light curing modes and filling techniques on microleakage of posterior resin composite restorations. Oper Dent. 2002;27(6):557-562. 


\section{Publish your work in this journal}

Clinical, Cosmetic and Investigational Dentistry is an international, peer-reviewed, open access, online journal focusing on the latest clinical and experimental research in dentistry with specific emphasis on cosmetic interventions. Innovative developments in dental materials, techniques and devices that improve outcomes and patient satisfac- tion and preference will be highlighted. The manuscript management system is completely online and includes a very quick and fair peerreview system, which is all easy to use. Visit http://www.dovepress. com/testimonials.php to read real quotes from published authors.

Submit your manuscript here: https://www.dovepress.com/clinical-cosmetic-and-investigational-dentistry-journal 